\title{
NIT2 overexpression predicts poor prognosis in tongue squamous cell carcinoma patients
}

\author{
Shan Chen ${ }^{1} \cdot$ Zengyan Wang $^{2} \cdot$ Chongjin Feng $^{1}$ (C)
}

Received: 11 July 2019 / Accepted: 12 November 2019 / Published online: 10 January 2020

(c) The Author(s) 2020

\begin{abstract}
There is disputable on the role of nitrilase-like 2 (NIT2) in cancer. Its expression and its relationship with clinicopathological features in tongue squamous cell carcinoma (TSCC) are not yet clear. The purpose of this study is to investigate the expression of NIT2 in TSCC and its correlation with clinicopathological characteristics in TSCC patients. Through proteomic identification, we found that the protein NIT2 was related to the development of TSCC. q-PCR, western blot and immunohistochemistry techniques were applied to detect the expression of NIT2 in TSCC. The relationship between the expression of NIT2 and clinicopathological features was analyzed by Chi square tests. The results showed the expression of NIT2 in TSCC was significantly higher than that in normal tongue tissues $(p<0.05)$. Univariate and multivariate analysis showed that the positive expression of NIT2 and N classification were associated with decreased disease-free survival rate (DFS) and overall survival (OS) $(p<0.05)$. The results suggested that NIT2 is overexpressed in TSCC and NIT2 may be a potential therapeutic target for TSCC.
\end{abstract}

Keywords Tongue squamous cell carcinoma $($ TSCC) $\cdot$ Prognosis $\cdot$ Survival $\cdot$ Proteome $\cdot$ Nitrilase-like 2

\section{Background}

The most common malignant oral and maxillofacial tumor is tongue squamous cell carcinoma (TSCC) with an increasing incidence year by year $[1,2]$. So far, the prognosis and

Shan Chen and Zengyan Wang have contributed equally to this work.

Electronic supplementary material The online version of this article (https://doi.org/10.1007/s11033-019-05197-5) contains supplementary material, which is available to authorized users.

Chongjin Feng

drfcj@aliyun.com

Shan Chen

chenshan00001@163.com

Zengyan Wang

wzengyan@hotmail.com

1 Department of Oral and Maxillofacial Surgery, The First Affiliated Hospital, Sun Yat-sen University, 58 Zhongshan Rd 2, Guangzhou 510080, Guangdong, People's Republic of China

2 Reproductive Medicine Center, The First Affiliated Hospital of Sun Yat-sen University, Guangzhou 510080, Guangdong, People's Republic of China treatment strategies of tongue cancer still rely on some traditional indicators, such as the classification of clinical tumor node metastasis (TNM), local lymph node metastasis, and the surgical margin [3-5]. However, these clinical prognostic factors still fail to predict prognosis in many cases of TSCC. Although progress has been made in research and treatment, the 5-year survival rate of TSCC patients is still low. Nowadays, biomarkers have become a research hotspot in tumor treatment and prognosis [6]. However, there is still no specific biomarker for recurrence and metastasis of tongue cancer.

Nitrilase 2 (NIT2), a member of the nitrilase superfamily, is a homologous protein of the mammalian tumor suppressor NIT1 with high sequence homology [7]; however, the function of NIT2 is not clear. Meister et al. found that there is an enzyme in the liver that can hydrolyze $\alpha$-ketoxipamide and $\alpha$-ketoglutarate monoamide. This enzyme can further deaminate the toxic substances produced by transamination of glutamine and asparagine to ammonia, and decompose them into reusable oxaloacetic acid and $\alpha$-ketoglutarate for the maintenance of health $[8,9]$. In 1972, Hersh proposed the enzyme catalytic reaction of NIT2 classified as $\omega$-amidase [10]. In 2009, Krasnikov et al. identified $\omega$-amidase that Meister found in the liver as the protein NIT2 [11, 12]. 
Recent studies have suggested that NIT2 is a candidate tumor suppressor protein [13] and that NIT2 overexpression appears to arrest the cell cycle in G2/M phase without inducing apoptosis [14]. However, another study has reported that NIT2 may be an oncogene in human colon cancer [15].

To date, the role of NIT2 in cancer is unclear, and thus the present study investigated the expression of NIT2 and its correlation with clinicopathological features in TSCC patients.

\section{Methods}

\section{Patients and tissue samples}

Three independent cohorts of 112 TSCC patients participated in our study. In cohort 1 and 2, 19 fresh TSCC samples and corresponding adjacent tissues $(1.5 \mathrm{~cm}$ away from the tumor resection margin, confirmed as tumor-free by intraoperative frozen biopsy) were collected from 19 patients who initially underwent malignant neoplasm resection at the First Affiliated Hospital of Sun Yat-sen University (Guangzhou, China) between June 2014 and July 2015. Three TSCC tissues and corresponding adjacent tissues tissues from cohort 1 were used for proteome analysis. Another 16 TSCC tissues and corresponding adjacent tissues in cohort 2 were used for western blot and quantitative reverse transcription-polymerase chain reaction (q-PCR). In cohort 3, 93 TSCC tissues from patients who were treated with malignant neoplasm resection between January 1999 and December 2012 at the same hospital were used for the survival analysis. The use of tissue samples in this study was approved by the Ethics Committee of the First Affiliated Hospital of Sun Yat-sen University.

\section{Proteome analysis}

Proteins were extracted and purified from TSCC tissues and adjacent tissues and then isoelectric focusing (IEF) was performed. In detail, protein samples were dissolved in $200 \mu \mathrm{l}$

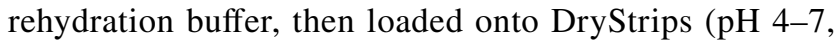
$24 \mathrm{~cm}$; BIORAD, USA). The rehydration buffer contained $7 \mathrm{M}$ urea (Amersham, Sweden), $2 \mathrm{M}$ thiourea (Amersham, Sweden), and 4\% CHAPS detergent (Usb, USA). IEF was performed using a Protean IEF Cell with an immobilized $\mathrm{pH}$ gradient (BIORAD, USA) at $20{ }^{\circ} \mathrm{C}$. After IEF, the gel strips were equilibrated with equilibration buffer ( $6 \mathrm{M}$ urea, $2 \%$ SDS, $50 \mathrm{mM}$ Tris-HCl pH 8.8, 30\% glycerol, $0.002 \%$ Bromophenol blue, $100 \mathrm{mM}$ DTT) for $15 \mathrm{~min}$, then placed into another equilibration buffer containing $2.5 \%$ iodoacetamide for 15 min. SDS-PAGE (12.5\%) was performed for two-dimensional gel electrophoresis (2-DE). After 2-DE, the gels were fixed for $30 \mathrm{~min}$ in fixative solution containing
$100 \mathrm{ml}$ ethanol, $25 \mathrm{ml}$ acetic acid, and $0.17 \mathrm{~g}$ anhydrous sodium acetate (plus distilled water to $250 \mathrm{ml}$ ), washed four times with distilled water, and stained ( $0.3 \mathrm{~g}$ Coomassie brilliant blue G-250, $25 \mathrm{~g}$ ammonium sulfate, $50 \mathrm{ml} 20 \%$ methanol, $25 \mathrm{ml} \mathrm{10 \%} \mathrm{phosphoric} \mathrm{acid,} \mathrm{and} \mathrm{distilled} \mathrm{water}$ to $250 \mathrm{ml}$ ). The 2-DE gels were scanned and analyzed using the Image Master 2D Platinum 5.0 (GE, USA) software. The spots where the gray value ratio was 1.5 times more between the two groups were screened as the differential protein spots. 2-DE gels were washed in water/acetonitrile 1:1 and then dehydrated in acetonitrile. The gel pieces were rehydrated in $50 \mu 1100 \mathrm{mM} \mathrm{NH} \mathrm{HCO}_{3}$ and $100 \mu \mathrm{l} 50 \%$ acetonitrile. Then the gel pieces were air-dried, rehydrated in $50 \mathrm{mM} \mathrm{NH}_{4} \mathrm{HCO}_{3}$ and $20 \mathrm{ng} / \mu \mathrm{l}$ trypsin, and incubated at $37^{\circ} \mathrm{C}$ for $12 \mathrm{~h}$. The supernatant was collected and peptides were extracted from the gel and the combined extracts were evaporated to dryness in a vacuum centrifuge. Mass analyses were performed with an ABI4800 mass spectrometer (MALDI-TOF/TOF, USA) and survey MS spectra from 700 to $3500 \mathrm{Da}$ were acquired. Proteins were identified by automated database spectra search (MASCOT, matrix-science) using the NCBI databases.

\section{Western blot analysis}

Total tissue protein was extracted, separated by $10 \%$ SDSPAGE, and transferred to the PVDF membrane (Amersham, Freiberg, Germany). The PVDF membrane was blocked for $1 \mathrm{~h}$ and then incubated with rabbit antibody against NIT2 (Proteintech, Chicago, IL, USA) or GAPDH antibody (Proteintech, Chicago, IL, USA) overnight at $4{ }^{\circ} \mathrm{C}$. The membranes were washed for 5-10 min three times with washing buffer and then second antibody was added at room temperature for $1 \mathrm{~h}$, which was followed by another three washes. The membranes were observed with chemiluminescence.

\section{Quantitative RT-PCR (q-PCR)}

Trizol (Thermo Fisher Scientific, USA) was used to extract total RNA from tissues. The specific primer sequences of NIT2 for RT-PCR were as follows: 5'-TGGAGGCTCTAT CCCTGAAGA-3', 5'-ACTATCACCCGGACTCAATGTT3' (Invitrogen). GAPDH (5'-TCCTCTGACTTCAACAGC GACAC-3', 5'-CACCCTGTTGCTGTAGCCAAATTC $-3^{\prime}$ ) was used as an endogenous control. Relative gene expressions of NIT2 were calculated as fold-change values (fold $=2^{-\Delta \Delta \mathrm{Ct}}$ ) by DataAssist v3.0 (Applied Biosystems).

\section{Tissue microarray}

Hematoxylin and eosin staining of sections of selected tumors were performed to pre-label representative tumor regions. A tissue core sample with a diameter of $2 \mathrm{~mm}$ 
was produced from each donor block using tissue microarray (Quick Ray) and placed in an empty paraffin wax with a maximum of 48 cores (UNITMA, Korea). Therefore, two kinds of tissue microarray blocks were constructed. Four-micron-thick sections were cut from the receptor block and transferred to the slide for hematoxylin and eosin staining to confirm the tumor tissue. It was found that two cases were adenocarcinoma, one case was lost during the experimental procedure, four cases exhibited serious defects, and three cases could not be tracked, as the complete follow-up data was not available. In the end, 93 samples were obtained from the two different tissue microarray blocks of TSCC (Fig. 1a).

\section{Immunohistochemistry}

NIT2 primary antibody was diluted (1:100) and secondary antibody was labeled with peroxidase and stained with 3,3'-diaminobenzidine (DAB). Sample tissues were sliced, routinely dewaxed, treated with hydrogen peroxide, antigen repaired, and washed with phosphate buffer (PBS). Five visual fields with $\times 400$ magnification were selected for each sample under a microscope and the results were assessed by the double-blind method. According to the staining intensity of cells and the proportion of positive cells, the expression of NIT2 was evaluated by multiplying the results of the two scores. Immunohistochemical staining was ranked into four grades: (0) colorless, (1) yellow, (2) yellow-brown, and (3) brown. The corresponding positive rates were ranked into four grades: (0) $0-25 \%$, (1) $26-50 \%$, (2) $51-75 \%$, and (3) $75-100 \%$. For statistical purposes, the specimens were divided into negative ( - ) expression ( $0-2$ points) and positive $(+)$ expression (3-9 points).

\section{Ethics approval and consent to participate}

Use of tissue for this study was approved by the Ethics Committee of the First Affiliated Hospital of Sun Yat-sen University [(2011) 69]. Written consent was obtained with all participants.

\section{Statistical analysis}

The experimental data were processed and analyzed by SPSS 18 and represented as mean \pm standard deviation (SD). The $\chi^{2}$ test was used to compare the correlation between NIT2 expression and clinicopathological features and the Wilcoxon test was used to detect the expression of NIT2 mRNA by qPCR and Western blot. Disease-free survival (DFS) and overall survival (OS) were calculated from operation date to recurrence date and death date, respectively. The survival curves were drawn by the Kaplan-Meier method

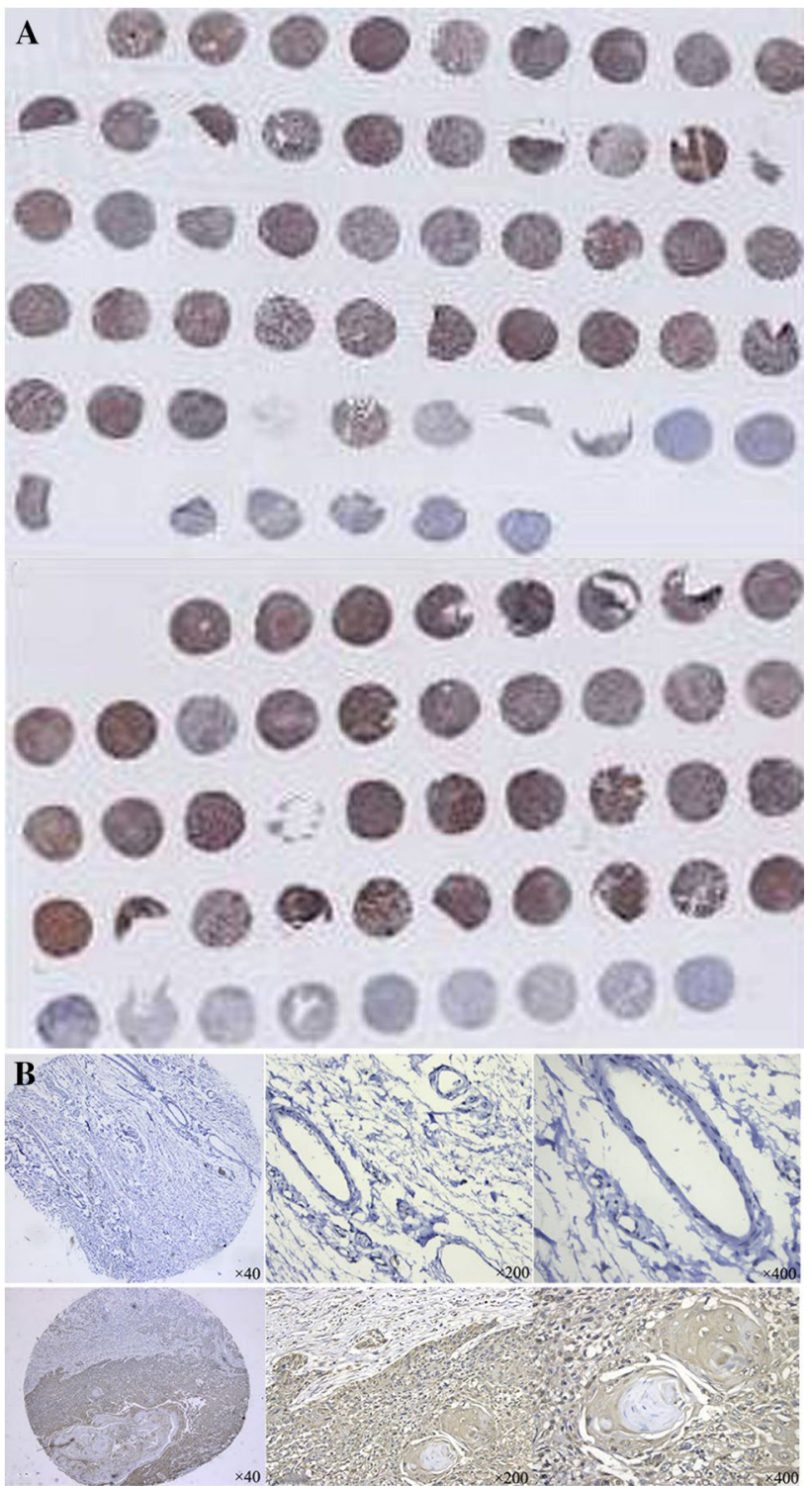

Fig. 1 Tissue microarray. a One hundred and three specimens were detected using tissue chip technique and 93 cases were finally available. Two cases were adenocarcinoma, one case was lost during the experimental procedure, four cases exhibited serious defects, and three cases could not be tracked, as the complete follow-up data was not available. In the end, 93 samples were obtained from the two different tissue microarray blocks of TSCC. b NIT2 was highly expressed in tongue cancer tissues by immunohistochemical staining, mainly in cytoplasm

and compared using the log-rank test. The Cox regression model was used for multivariate analysis. $\mathrm{p}<0.05$ indicates that the difference is statistically significant. 


\section{Results}

\section{Proteomic analyses identified altered protein expression in TSCC}

Representative gel images of the protein in TSCC and adjacent tissue are shown in Fig. 2. A comparison of the 2-DE images revealed that six protein spots were up-regulated in TSCC $(\mathrm{T} / \mathrm{N}>1.5)$ and 11 protein spots were down-regulated in TSCC (N/T $>1.5)$. Finally, 13 proteins were identified from 17 spots by mass spectrometry (Table 1). As the role of NIT2 in cancer is unclear, we selected this protein for further study.

Western blot analysis and q-PCR were performed on 16 pairs of TSCC and adjacent tissues to explore the expression of NIT2. Western blotting demonstrated that NIT2 protein was overexpressed in twelve TSCC tissues

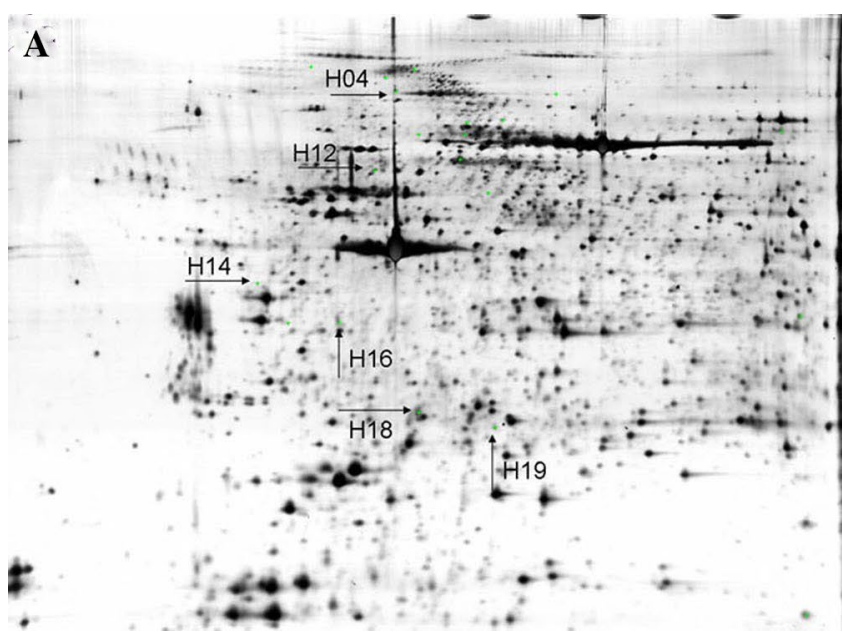

Fig. 2 Representative 2-DE images of differentially expressed proteins isolated from TSCC and adjacent tissue. a Representative 2-DE images of differentially expressed proteins isolated from adjacent non-tumor tissue. Significantly up-regulated spots $(\mathrm{N} / \mathrm{T}>1.5)$ in para-

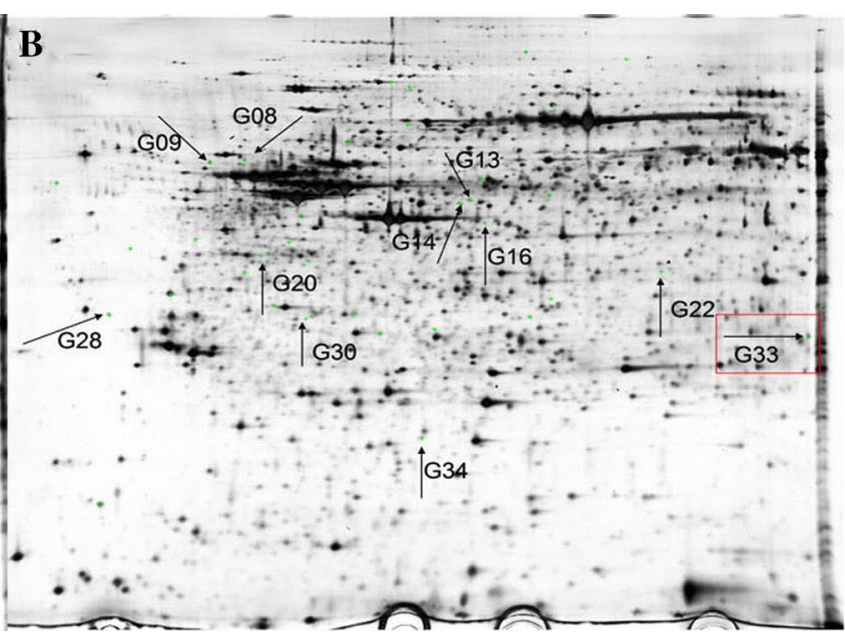

carcinoma tissues of tongue are marked with numbers. b Representative 2-DE images of differentially expressed proteins isolated from TSCC samples. Significantly up-regulated spots $(\mathrm{T} / \mathrm{N}>1.5)$ in TSCC are marked with numbers
Table 1 Identified different protein expressions between TSCC and adjacent nontumor tissues

\begin{tabular}{lllllll}
\hline No. & Proteins name & Protein AC & pI & MASS & $\begin{array}{l}\text { MASCOT } \\
\text { score }\end{array}$ & $\begin{array}{l}\text { Sequence } \\
\text { coverage } \\
(\%)\end{array}$ \\
& & & & & & 15 \\
\hline G08 & Endoplasmin, HSP90B1 & ENPL & 4.76 & 92,696 & 189 & 15 \\
G09 & Endoplasmin, HSP90B1 & ENPL & 4.76 & 92,696 & 173 & 17 \\
G13 & Ezrin & EZRI & 5.94 & 69,484 & 74 & 26 \\
G14 & Keratin, type II cytoskeletal & K2C6A & 8.09 & 60,293 & 193 & 28 \\
G16 & Keratin, type II cytoskeletal & K2C6A & 8.09 & 60,293 & 222 & 44 \\
G20 & Actin, alpha skeletal muscle & ACTS & 5.23 & 42,366 & 252 & 20 \\
G22 & Keratin, type I cytoskeletal 10 & K1C10 & 5.13 & 59,020 & 143 & 20 \\
G28 & Clathrin light chain A & CLCA & 4.43 & 27,174 & 154 & 34 \\
G30 & Keratin, type I cytoskeletal 14 & K1C14 & 5.09 & 51,872 & 186 & 34 \\
G33 & Omega-amidase NIT2 & NIT2 & 6.82 & 30,988 & 251 & 43 \\
G34 & Inosinetriphosphate pyrophosphatase & ITPA & 5.5 & 21,831 & 150 & 50 \\
H04 & Actin, alpha skeletal muscle & ACTS & 5.23 & 42,366 & 411 & 27 \\
H12 & Alpha-actinin-2 & F6THM6 & 5.41 & 80,081 & 221 & 38 \\
H14 & Keratin, type I cytoskeletal 13 & K7ERE3 & 4.76 & 45,574 & 294 & 17 \\
H16 & Suppressor of G2 allele of SKP1 & SUGT1 & 5.07 & 41,284 & 124 & 52 \\
H18 & Actin, alpha skeletal muscle & ACTS & 5.23 & 42,366 & 341 & 28 \\
H19 & Keratin, type I cytoskeletal 16 & K1C16 & 4.99 & 51,578 & 334 & \\
\hline & & & & & & \\
\hline
\end{tabular}




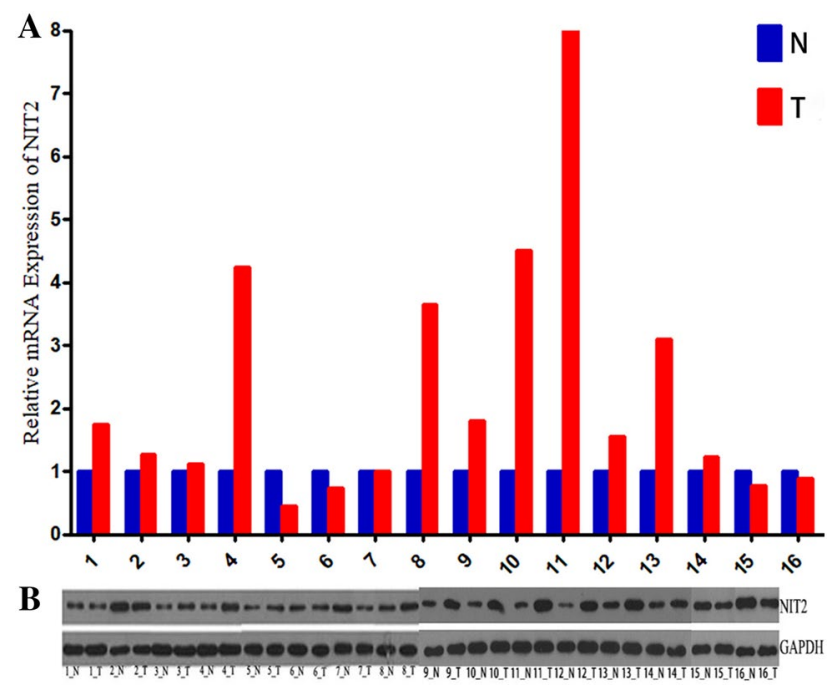

Fig. 3 Expression of NIT2 in TSCC by Western Blot and qPCR. N, adjacent normal tissues of tongue; T, TSCC tissue. $(p=0.026(\mathbf{a}), p$ $<0.001(\mathbf{b}))$

compared with their adjacent tissues, whereas in four samples NIT2 protein expression was higher in adjacent tissues compared to TSCC tissues (Fig. 3b, p=0.008). q-PCR also showed similar results. NIT2 mRNA in twelve TSCC tissues was higher than that in adjacent tissues, whereas in four cases NIT2 mRNA in adjacent tissues was higher than that in TSCC tissues (Fig. 3a, p=0.01). The difference between TSCC and adjacent tissues was statistically significant. These results demonstrate that NIT2 is highly expressed in TSCC tissues.

\section{NIT2 expression was detected by immunohistochemistry}

Immunohistochemistry on paraffin sections showed that the localization of NIT2 protein was mainly in the cytoplasm. NIT2 staining was strong in TSCC tissues and weak in adjacent tissues (Fig. 1a). The positive expression rate of NIT2 in 93 cases of TSCC was $71.0 \%$.

\section{The relationship between NIT2 overexpression and clinicopathological parameters in TSCC patients}

As summarized in Table 2, analysis of 93 TSCC samples indicated that NIT2 overexpression was significantly associated with classification of lymph node metastasis ( $\mathrm{N}$ classification) $(\mathrm{p}=0.008)$. In contrast, there was no significant relationship between NIT2 protein level and variables including age, gender, smoking history, and tumor grade $(\mathrm{p}>0.05)$.
Table 2 Correlation between NIT2 and clinicopathologic variables of TSCC patients

\begin{tabular}{|c|c|c|c|c|}
\hline \multirow[t]{2}{*}{ Variables } & \multirow[t]{2}{*}{ Cases } & \multicolumn{2}{|l|}{ NIT2 } & \multirow[t]{2}{*}{$p$} \\
\hline & & Negative (\%) & Positive (\%) & \\
\hline \multicolumn{5}{|c|}{ Age (years) } \\
\hline$\leq 60$ & 67 & $21(31.3)$ & $46(68.7)$ & \\
\hline$>60$ & 26 & $9(34.6)$ & $17(65.4)$ & 0.783 \\
\hline \multicolumn{5}{|l|}{ Gender } \\
\hline Male & 57 & 18 (31.6) & $39(68.4)$ & \\
\hline Female & 36 & $14(38.9)$ & $22(61.1)$ & 0.594 \\
\hline \multicolumn{5}{|c|}{ Smoking history } \\
\hline Yes & 26 & $8(30.8)$ & $18(69.2)$ & \\
\hline No & 67 & $25(37.3)$ & $42(62.7)$ & 0.552 \\
\hline \multicolumn{5}{|c|}{$\mathrm{N}$ classification } \\
\hline Negative & 42 & $21(50.0)$ & $21(50.0)$ & \\
\hline Positive & 51 & $12(23.5)$ & $39(76.5)$ & 0.008 \\
\hline \multicolumn{5}{|c|}{$\mathrm{T}$ classification } \\
\hline $\mathrm{T} 1-\mathrm{T} 2$ & 82 & $28(34.1)$ & $54(65.9)$ & \\
\hline T3-T4 & 11 & $5(45.5)$ & $6(54.5)$ & 0.492 \\
\hline \multicolumn{5}{|c|}{ Clinic stage (TNM) } \\
\hline I-II & 46 & $15(32.6)$ & $31(67.4)$ & \\
\hline III-IV & 47 & $19(40.4)$ & $28(59.6)$ & 0.572 \\
\hline
\end{tabular}

TSCC tongue squamous cell carcinoma

\section{The relationship between NIT2 protein expression and DFS and OS in TSCC patients}

Patients with TSCC were followed up for 2-163 months (median: 70 months). At the end of the follow-up, 50 patients survived without local recurrence and 38 patients developed cervical lymph node metastasis 2-154 months after surgery (median: 37 months). The 1-, 3-, and 5-year DFS rates were $78.4 \%, 74.3 \%$, and $72.0 \%$ in the NIT2-positive group and $96.7 \%, 91.7 \%$, and $89.2 \%$ in the negative group, respectively ( $\mathrm{p}=0.001$, Table 3, Fig. 4a). The 1-, 3-, and 5-year OS rates were $80.3 \%, 60.6 \%$, and $52.9 \%$ in the NIT2-positive group and $88.9 \%, 77.8 \%$, and $74.1 \%$ in the negative group, respectively ( $\mathrm{p}=0.005$, Table 3 , Fig. $4 \mathrm{~b}$ ). The DFS and OS rate of NIT2-positive patients was significantly shorter than that of NIT2-negative patients.

\section{The correlation between NIT2 expression and TSCC prognosis}

Univariate analysis showed that $\mathrm{N}$ classification $(\mathrm{p}=0.002$, Table 3, Fig. 4c) and the positive expression of NIT2 $(p=0.001$, Table 3, Fig. 4a) were related to shorter DFS. Multivariate Cox regression analysis indicated that NIT2 positive expression $(\mathrm{p}=0.0145$, Table 4$), \mathrm{N}$ classification $(p=0.006$, Table 4), and TNM $(p=0.009$, Table 4) predicted shorter DFS and were independent prognostic 
Table 3 Prognostic factors for DFS and OS by univariate analysis

\begin{tabular}{|c|c|c|c|c|c|c|c|c|c|}
\hline \multirow[t]{2}{*}{ Variables } & \multirow[t]{2}{*}{$\mathrm{n}$} & \multicolumn{4}{|l|}{ DFS } & \multicolumn{4}{|l|}{ OS } \\
\hline & & 1-year (\%) & 3-year (\%) & 5 -year (\%) & $p$ & 1-year (\%) & 3-year (\%) & 5 -years (\%) & $p$ \\
\hline \multicolumn{10}{|l|}{ Age (years) } \\
\hline$\leq 60$ & 66 & 89.0 & 83.2 & 81.0 & & 81.8 & 62.0 & 56.7 & \\
\hline$>60$ & 27 & 73.2 & 68.9 & 68.9 & 0.095 & 85.2 & 63.0 & 51.9 & 0.443 \\
\hline \multicolumn{10}{|l|}{ Sex } \\
\hline Male & 57 & 80.2 & 76.0 & 73.6 & & 84.2 & 61.4 & 56.1 & \\
\hline Female & 36 & 91.4 & 84.1 & 84.1 & 0.415 & 80.6 & 69.4 & 63.8 & 0.877 \\
\hline \multicolumn{10}{|l|}{ Smoking } \\
\hline Yes & 26 & 84.4 & 80.0 & 80.0 & & 79.1 & 65.7 & 61.1 & \\
\hline No & 67 & 84.4 & 78.8 & 76.7 & 0.904 & 92.3 & 65.4 & 53.8 & 0.822 \\
\hline \multicolumn{10}{|c|}{ N classification } \\
\hline N0 & 55 & 92.0 & 81.2 & 73.0 & & 95.2 & 83.3 & 76.0 & \\
\hline N1-N3 & 38 & 61.2 & 46.8 & 40.4 & 0.002 & 72.0 & 50.0 & 44.0 & $<0.01$ \\
\hline \multicolumn{10}{|c|}{$\mathrm{T}$ classification } \\
\hline $\mathrm{T} 1-\mathrm{T} 2$ & 82 & 83.7 & 77.4 & 75.7 & & 82.9 & 64.6 & 58.5 & \\
\hline T3-T4 & 11 & 90.9 & 90.9 & 90.9 & 0.283 & 81.8 & 72.7 & 63.5 & 0.441 \\
\hline \multicolumn{10}{|c|}{ Clinic stage (TNM) } \\
\hline I-II & 46 & 89.1 & 81.6 & 78.8 & & 91.3 & 73.9 & 67.4 & \\
\hline III-IV & 47 & 79.7 & 76.7 & 76.7 & 0.943 & 74.5 & 57.4 & 51.1 & 0.112 \\
\hline \multicolumn{10}{|l|}{ NIT2 } \\
\hline Negative & 27 & 96.7 & 91.7 & 89.2 & & 88.9 & 77.8 & 74.1 & \\
\hline Positive & 66 & 78.4 & 74.3 & 72.0 & 0.001 & 80.3 & 60.6 & 52.9 & 0.005 \\
\hline
\end{tabular}

$D F S$ disease-free survival, $O S$ overall survival indicators of TSCC. On the other hand, univariate analysis and Kaplan-Meier survival curves revealed that NIT2 positive expression ( $p=0.005$, Table 3, Fig. 4b) and lymph node metastasis ( $p<0.01$, Table 3 , Fig. $4 d$ ) were statistically significant. Multivariate Cox regression analysis indicated that positive NIT2 expression ( $p=0.015$, Table 4$)$, lymph node metastasis ( $\mathrm{p}=0.005$, Table 4$)$, and TNM ( $\mathrm{p}=0.045$, Table 4) were associated with OS and were independent factors for shorter OS of patients with TSCC.

\section{Discussion}

To date, the TNM staging system is still the main basis for treatment strategies and prognosis of tongue cancer. Moreover, some studies have reported that clinical indicators such as regional lymph node metastasis status [16] are of significance in the poor prognosis of patients with TSCC. In previous research, we found that lymph node metastasis predicted a poor prognosis for TSCC [17]. Consistent with these findings, TNM and lymph node metastasis are significant for the poor prognosis of TSCC in this study. Even so, the risk classification system of TSCC is still unsatisfactory.

TSCC is a multifactorial disease caused by multiple genetic changes and environmental factors $[1,2]$. With the rapid development of molecular biology, molecular targeted therapy plays an important part in the treatment of tumors, as it is of great clinical significance to define a target gene for specific and differentiated treatment. By detecting the expression of a particular gene, the tumor can be detected as early as possible and its expression can be regulated by specific activators or blockers that affect its downstream pathway by inhibiting the proliferation, invasion, or migration of tumor cells or by promoting apoptosis of cancer cells [18]. However, the molecular mechanisms of the development and metastasis of TSCC are still unclear, which greatly impedes the application of molecular targeted therapy in the treatment of TSCC. Therefore, the exploration of gene therapy targets and prognostic indicators for effective treatment of TSCC is an important issue that needs to be researched. Using 2-DE combined with MS analysis, we successfully identified NIT2 as a novel biomarker in TSCC tissues.

The nitrilase superfamily is divided into 13 branches and is widely distributed in nature [19-21]. Human nitrilase (NIT) proteins belong to the nitrilase superfamily and contain two proteins, namely NIT1 (nitrilase-like protein 1) and NIT2 (nitrilase-like protein 2) [21, 22]. NIT2 shares $40 \%$ sequence identity [22] and 55\% homology [14] with NIT1. NIT2, identified as $\omega$-amidase, plays an important metabolic role by catalyzing hydrolysis of $\alpha$-ketoglutaramate and $\alpha$-ketosuccinamate, yielding $\alpha$-ketoglutarate and oxaloacetate, respectively $[8,9]$. Some studies have speculated that 
A

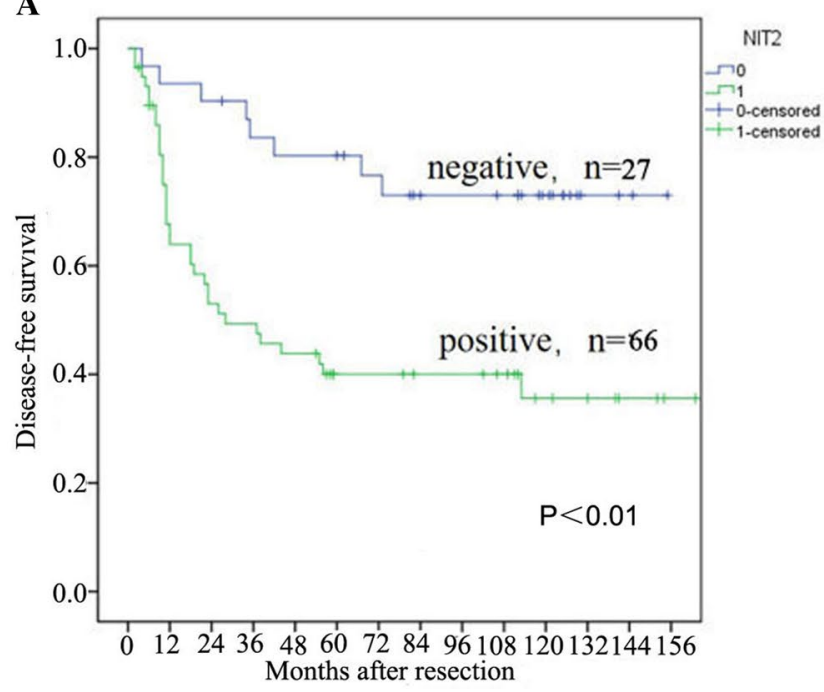

C

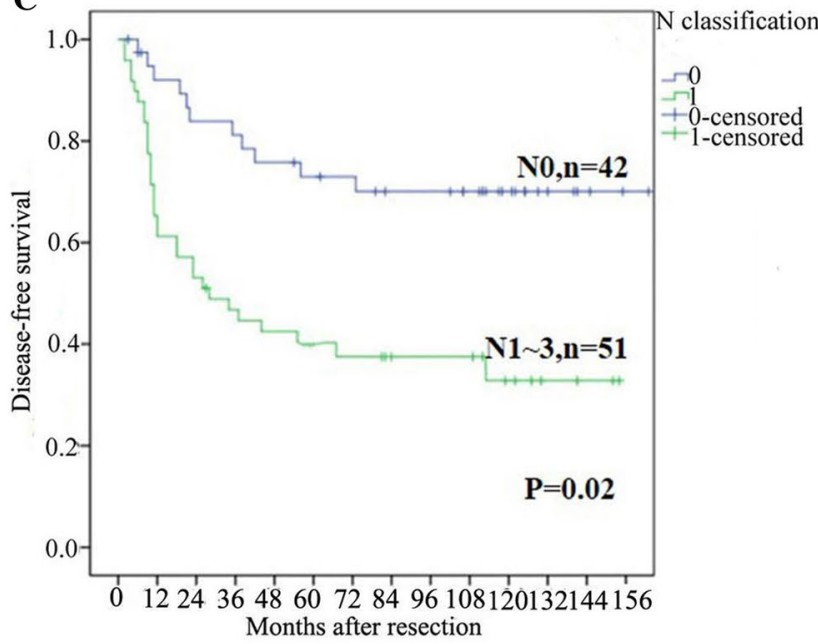

Fig. 4 Kaplan-Meier survival curves of patients with TSCC after radical tongue cancer resection. The patients were divided into negative group and positive group of NIT2. Disease-free survival $(p=0.001$, log-rank, a) and overall survival $(p=0.005$, log-rank, b) of patients with positive group was shorter than those with nega-
B

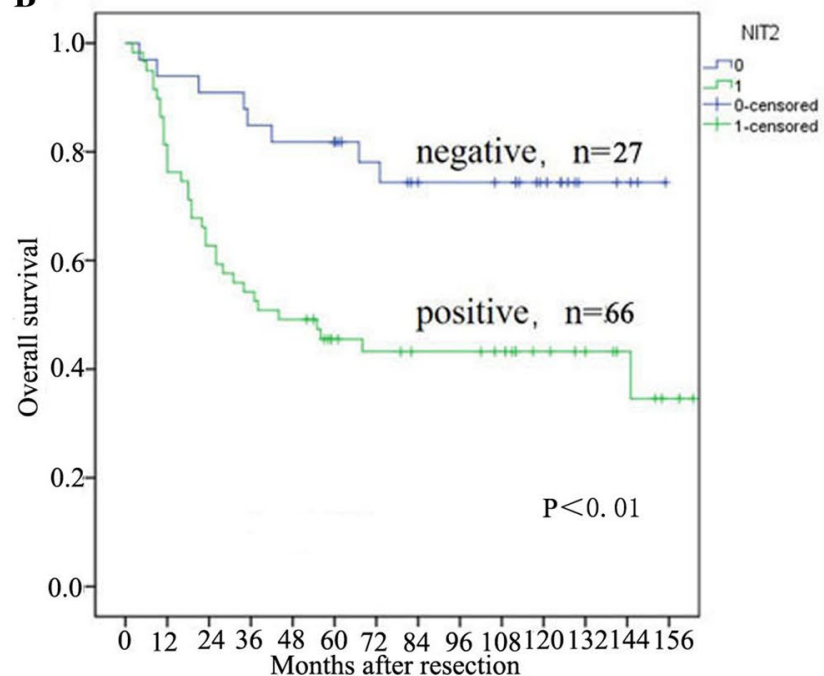

D

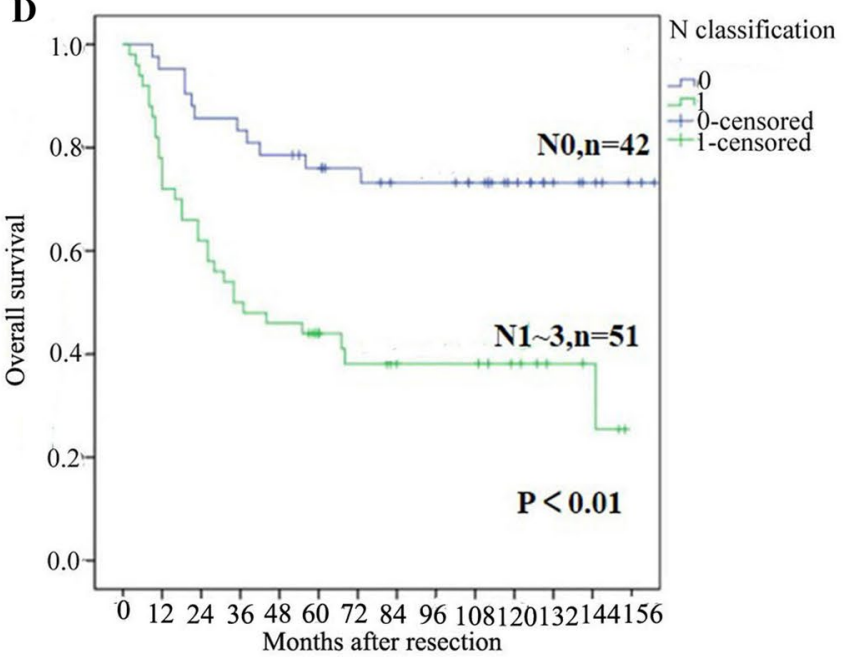

tive group. $\mathbf{c}$ and $\mathbf{d}$ Kaplan-Meier survival curves of $\mathrm{N}$ classification for patients with TSCC after radical tongue cancer resection. The patients were divided into N0 group and N1-N3 group. Disease-free survival ( $p=0.002$, log-rank) and overall survival $(p<0.01$, log-rank) of patients with N1-N3 group was shorter than those with N0 group
Table 4 Prognostic factors for DFS and OS by multivariate Cox proportional hazards regression model

\begin{tabular}{|c|c|c|c|c|c|c|c|}
\hline \multirow[t]{2}{*}{ Variables } & \multicolumn{3}{|l|}{ DFS } & \multirow[t]{2}{*}{ Variables } & \multicolumn{3}{|l|}{ OS } \\
\hline & HR & $95 \% \mathrm{CI}$ & $p$ & & HR & $95 \% \mathrm{CI}$ & $p$ \\
\hline NIT2 & 2.789 & $1.230-6.326$ & 0.014 & NIT2 & 2.713 & $1.218-6.047$ & 0.015 \\
\hline $\mathrm{N}$ classification & 3.131 & $1.397-7.020$ & 0.006 & $\mathrm{~N}$ classification & 2.972 & $1.379-6.408$ & 0.005 \\
\hline TNM & 2.441 & $1.252-4.758$ & 0.009 & TNM & 1.96 & $1.015-3.782$ & 0.045 \\
\hline
\end{tabular}

$H R$ hazard ratio, $C I$ confidence interval. Other abbreviations as in Table
NIT2 is a potential tumor suppressor [23], whereas other studies have suggested that NIT2 is a carcinogenic protein in colon cancer [15]. The role of NIT2 in cancer remains elusive and, to the best of our knowledge, no study to date has reported the role of NIT2 in TSCC.
In this study, we presented the first evidence of NIT2 overexpression in TSCC. Furthermore, we evaluated the possibility of using NIT2 as a potential clinical indicator to identify aggressive TSCC as well as its prognostic value for patient survival in cancer. Immunostaining demonstrated 
that the high expression level of NIT2 significantly correlated with reduced DFS time of TSCC patients. Taken together, our present results are consistent with previous studies [15, 23] and suggests that NIT2 might represent a valuable prognostic indicator for differentiating aggressive TSCC. However, the mechanisms of NIT2 tumorigenic effects in TSCC have not been elucidated. NIT2 may be an oncogene in human colon cancer, as its downregulation triggers the apoptosis of colon cancer cells through the caspase-3 and poly (ADP-ribose) polymerase pathways [15]. Activation of caspase- 3 has been reported to play a key role in inducing apoptosis [24] and the deregulation of caspase-3 is a frequent event in TSCC $[25,26]$. Thus we hypothesize that NIT2 promotes the development of TSCC by activating caspase- 3 pathways. This warrants further research to investigate the mechanisms of the tumorigenic effects of NIT2 in TSCC.

In conclusion, our data have demonstrated that NIT2 is highly expressed in TSCC. NIT2 is an independent indicator of prognosis in patients with TSCC after radical resection and may serve as a potential therapeutic target in TSCC.

Funding This study was founded by the Grants of the National Natural Science Foundation of China (No. 81172564). The funders had no role in study design, data collection and analysis, decision to publish, or preparation of the manuscript.

\section{Compliance with ethical standards}

Conflicts of interest The authors declare no conflict of interest.

Open Access This article is licensed under a Creative Commons Attribution 4.0 International License, which permits use, sharing, adaptation, distribution and reproduction in any medium or format, as long as you give appropriate credit to the original author(s) and the source, provide a link to the Creative Commons licence, and indicate if changes were made. The images or other third party material in this article are included in the article's Creative Commons licence, unless indicated otherwise in a credit line to the material. If material is not included in the article's Creative Commons licence and your intended use is not permitted by statutory regulation or exceeds the permitted use, you will need to obtain permission directly from the copyright holder. To view a copy of this licence, visit http://creativecommons.org/licenses/by/4.0/.

\section{References}

1. Almangush A, Heikkinen I, Mäkitie AA, Coletta RD, Läärä E, Leivo I, Salo T (2017) Prognostic biomarkers for oral tongue squamous cell carcinoma: a systematic review and meta-analysis. Br J Cancer 117(6):856-866

2. Ng JH, Iyer NG, Tan MH, Edgren G (2017) Changing epidemiology of oral squamous cell carcinoma of the tongue: a global study. Head Neck 39(2):297-304

3. Moeckelmann N, Ebrahimi A, Tou YK, Gupta R, Low TH, Ashford B, Ch'ng S, Palme CE, Clark JR (2018) Prognostic implications of the 8th edition American Joint Committee on Cancer (AJCC) staging system in oral cavity squamous cell carcinoma. Oral Oncol. 85:82-86

4. Goldstein DP, Bachar GY, Lea J, Shrime MG, Patel RS, Gullane PJ, Brown DH, Gilbert RW, Kim J, Waldron J, Perez-Ordonez B, Davis AM, Cheng L, Xu W, Irish JC (2013) Outcomes of squamous cell cancer of the oral tongue managed at the Princess Margaret Hospital. Head Neck 35:632-641

5. Okura M, Iida S, Aikawa T, Adachi T, Yoshimura N, Yamada T, Kogo M (2008) Tumor thickness and paralingual distance of coronal MR imaging predicts cervical node metastases in oral tongue carcinoma. AJNR Am J Neuroradiol 29(1):45-50

6. Cals FL, Koljenovic S, Hardillo JA, Baatenburg DJR, Bakker ST, Puppels GJ (2016) Development and validation of Raman spectroscopic classification models to discriminate tongue squamous cell carcinoma from non-tumorous tissue. Oral Oncol 60:41-47

7. Barglow KT, Cravatt BF (2006) Substrate mimicry in an activitybased probe that targets the nitrilase family of enzymes. Angew Chem Int Ed Engl 45(44):7408-7411

8. Meister A, Levintow L, Greenfield RE, Abendschein PA (1955) Hydrolysis and transfer reactions catalyzed by omega-amidase preparations. J Biol Chem 215:441-460

9. Meister A (1953) Preparation of enzymatic reactions of the keto analogues of asparagine and glutamine. J Biol Chem 200:571-589

10. Hersh LB (1972) Rat liver-amidase. Kinetic evidence for an acylenzyme intermediate. Biochemistry. 11:2251-2256

11. Krasnikov BF, Nostramo R, Pinto JT, Cooper AJ (2009) Assay and purification of omega-amidase/Nit2, a ubiquitously expressed putative tumor suppressor, that catalyzes the deamidation of the $\alpha$-keto acid analogues of glutamine and asparagine. Anal Biochem 391:144-150

12. Krasnikov BF, Chien CH, Nostramo R, Pinto JT, Nieves E, Callaway M, Sun J, Huebner K, Cooper AJ (2009) Identification of the putative tumor suppressor Nit2 as omega-amidase, an enzyme metabolically linked to glutamine and asparagine transamination. Biochimie 91:1072-1080

13. Sugiyama A, Miyagi Y, Komiya Y, Kurabe N, Kitanaka C, Kato N, Nagashima Y, Kuchino Y, Tashiro F (2003) Forced expression of antisense 14-3-3 $\beta$ RNA suppresses tumor cell growth in vitro and in vivo. Carcinogenesis 24:1549-1559

14. Lin CH, Chung MY, Chen WB, Chien CH (2007) Growth inhibitory effect of the human NIT2 gene and its allelic imbalance in cancers. FEBS J 274:2946-2956

15. Zheng B, Chai R, Yu X (2015) Downregulation of NIT2 inhibits colon cancer cell proliferation and induces cell cycle arrest through the caspase- 3 and PARP pathways. Int J Mol Med. 35(5):1317-1322

16. Bernier J, Cooper JS, Pajak TF, van Glabbeke M, Bourhis J, Forastiere A, Ozsahin EM, Jacobs JR, Jassem J, Ang KK, Lefèbvre JL (2005) Defining risk levels in locally advanced head and neck cancers: a comparative analysis of concurrent postoperative radiation plus chemotherapy trials of the EORTC (\#22931) and RTOG (\# 9501). Head Neck 27:843-850

17. Chen S, Guo J, Feng C, Ke Z, Chen L, Pan Y (2016) The preoperative platelet-lymphocyte ratio versus neutrophil-lymphocyte ratio: which is better as a prognostic factor in oral squamous cell carcinoma? Ther Adv Med Oncol 8(3):160-167

18. Miyachi H (2015) Molecular-genetic diagnosis and moleculartargeted therapy in cancer: challenges in the era of precision medicine. Rinsho Byori 63(10):1188-1193

19. Pace HC, Brenner C (2001) The nitrilase superfamily: classification, structure and function. Genome Biol 2(1):REVIEWS0001

20. Horst RJ, Zeh C, Saur A, Sonnewald S, Sonnewald U, Voll LM (2012) The Ustilago maydis Nit2 homolog regulates nitrogen utilization and is required for efficient induction of filamentous growth. Eukaryot Cell 11:368-380 
21. Pace HC, Hodawadekar SC, Draganescu A, Huang J, Bieganowski P, Pekarsky Y, Croce CM, Brenner C (2000) Crystal structure of the worm NitFhit Rosetta Stone protein reveals a Nit tetramer binding two Fhit dimers. Curr Biol 10:907-917

22. Barglow KT, Saikatendu KS, Bracey MH, Huey R, Morris GM, Olson AJ, Stevens RC, Cravatt BF (2008) Functional proteomic and structural insights into molecular recognition in the nitrilase family enzymes. Biochemistry 47:13514-13523

23. Krasnikov BF, Chien CH, Nostramo R, Pinto JT, Nieves E, Callaway M, Sun J, Huebner K, Cooper AJ (2009) Identification of the putative tumor suppressor Nit2 as $\omega$-amidase, an enzyme metabolically linked to glutamine and asparagine transamination. Biochimie 91(9):1072-1080

24. Khan SM, Dauffenbach LM, Yeh J (2000) Mitochondria and caspases in induced apoptosis in human luteinized granulosa cells. Biochem Biophys Res Commun 269:542-545
25. Andressakis D, Lazaris AC, Tsiambas E, Kavantzas N, Rapidis A, Patsouris E (2008) Evaluation of caspase- 3 and caspase-8 deregulation in tongue squamous cell carcinoma, based on immunohistochemistry and computerised image analysis. J Laryngol Otol 122(11):1213-1218

26. Zhang YX, Yu SB, Ou-Yang JP, Xia D, Wang M, Li JR (2005) Effect of protein kinase $\mathrm{C}$ alpha, caspase-3, and survivin on apoptosis of oral cancer cells induced by staurosporine 1 . Acta Pharmacol Sinica 26(11):1365-1372

Publisher's Note Springer Nature remains neutral with regard to jurisdictional claims in published maps and institutional affiliations. 